\title{
Vanishing hypercalciuric kidney stones after treating underlying acromegaly
}

Eline van der Valk, Tom Tobe, Aline Stades ${ }^{1}$ and Alex Muller

Diakonessenhuis Utrecht, Department of Internal Medicine, Postbus 80250, 3508 TG Utrecht, The Netherlands

${ }^{1}$ UMC Utrecht, Department of Endocrinology, Postbus 85500, 3508 GA Utrecht, The Netherlands
Correspondence

should be addressed to

E van der Valk

Email

elinevandervalk@gmail.com

\section{Summary}

A 53-year-old male presented with recurrent calcium oxalate kidney stones as a first sign of underlying acromegaly, which vanished when his acromegaly was controlled. The exact mechanism behind hypercalciuria and urolithiasis in acromegaly is not yet clear. By discussing this case, a short overview of the pathophysiology of hypercalciuria in acromegaly and practical insights are given.

\section{Learning points}

- Hypercalciuria is a common finding in acromegaly.

- There are only few reports describing hypercalciuric kidney stones in acromegaly.

- We assume that in acromegaly there is a primary role of IGF1-mediated, PTH-independent increase in calcitriol synthesis resulting in hypercalciuric kidney stones.

\section{Background}

Acromegaly is a multisystem disease with rheumatological, cardiovascular, respiratory and metabolic consequences (1). A frequent metabolic consequence is hypercalciuria (2) (3). Although several studies have been published on this subject, the exact mechanism is not yet clear. Moreover, nephrolithiasis with calcium-containing stones occurs more frequently in patients with acromegaly, presumably as a consequence of this hypercalciuria (2) (4) (5) (6) (7).

Here, we report a case of a patient in whom calcium oxalate kidney stones led to an underlying diagnosis of acromegaly and in whom treatment of acromegaly resulted in the disappearance of these kidney stones.

\section{Case presentation}

A 53-year-old male with a medical history of hypertension, type 2 diabetes mellitus, osteoarthritis and obstructive sleep apnoea was referred because of recurrent kidney \footnotetext{
open 2 access $(c)\left(\begin{array}{l}\text { This work is licensed under a Creative Commons } \\ \text { Attribution-NonCommercial-NoDerivs } 3.0\end{array}\right.$ Unported License.

stones. For the past 18 months, he had excreted approximately one renal stone each month. Other symptoms included dental problems, an enlarged tongue, thickened skin, increased perspiration and enlarged feet and hands that had developed over the past few years. Besides his acromegalic features, the physical examination was normal. Analysis of the stones revealed that they were made up of $100 \%$ calcium oxalate. Additional testing showed normal concentrations of calcium, phosphate, parathyroid hormone (PTH) and vitamin D and normal urinary phosphate excretion (Table 1). There was no evidence of sarcoidosis, as an X-ray showed no abnormalities, and angiotensin-converting enzyme levels were normal.

\section{Investigation}

Considering the clinical presentation, acromegaly was suspected and the IGF1 level was found to be significantly increased. MRI of the brain revealed a pituitary

$\begin{array}{rr}\text { (C) } 2013 \text { The authors } & \text { http://www.edmcasereports.com } \\ \text { Published by Bioscientifica Ltd }\end{array}$


Table 1 Biochemical and hormonal parameters in active and controlled acromegaly.

\section{Biochemical and hormonal parameters}

Plasma albumin ( $\mathrm{g} / \mathrm{l})$

Creatinine ( $\mu \mathrm{mol} / \mathrm{l})$

Calculated clearance $(\mathrm{ml} / \mathrm{min})$

Plasma Ca (mmol/l)

Albumin-corrected plasma calcium ( $\mathrm{mmol} / \mathrm{l})$

Plasma Mg (mmol/l)

Plasma $\mathrm{PO}_{4}(\mathrm{mmol} / \mathrm{l})$

Serum IGF1 (ng/ml)

Plasma PTH (pmol/l)

Plasma 25-OH-vitamin D

Plasma 1,25(OH) $)_{2}$-vitamin D

24-h $\mathrm{U}$ volume (I/24 h)

24-h U creatinine excretion ( $\mathrm{mmol} / 24 \mathrm{~h}$ )

24-h U calcium excretion (mmol/24 h)

24-h $\mathrm{U} \mathrm{PO}_{4}$ excretion ( $\mathrm{mmol} / 24 \mathrm{~h}$ )

24-h oxalate excretion ( $\mu \mathrm{mol} / 24 \mathrm{~h}$ )

24-h citrate excretion (mmol/24 h)

\begin{tabular}{l}
\hline Active acromegaly \\
\hline 42.5 \\
95 \\
129 \\
2.43 \\
2.5 \\
0.72 \\
1.45 \\
762 \\
2.9 \\
72.6 \\
Not available \\
2000 \\
18.5 \\
6.0 \\
29.8 \\
672 \\
4.52 \\
\end{tabular}

\begin{tabular}{l}
\hline Controlled acromegaly \\
\hline 43 \\
123 \\
96 \\
2.28 \\
2.2 \\
0.79 \\
1.22 \\
161 \\
7.7 \\
53.7 \\
85.7 \\
1950 \\
16.8 \\
2.0 \\
45.8 \\
522 \\
1.28 \\
\hline
\end{tabular}

macro-adenoma with supra- and parasellar extension (Fig. 1). There was secondary hypogonadism, but pituitaryadrenal and pituitary-thyroid axes were unaffected.

\section{Treatment}

The patient was referred for neurosurgery and prescribed a long-acting somatostatin analogue.

\section{Outcome and follow-up}

After initiation of treatment with a somatostatin analogue, excessive perspiration disappeared, the apnoeas were less frequent and the frequency of hypoglycaemia increased. Hypertension was better controlled. Nine months after diagnosis, the patient underwent endoscopic transnasal transsphenoidal selective adenomectomy without complications. After the operation and after cessation of the somatostatin analogue treatment, his IGF1 level was normal and he became normoglycaemic without medication. Calcium excretion normalised, and no kidney stones have been passed since then.

Interestingly, a direct correlation between calcium excretion and IGF1 is seen (Fig. 2). This corresponds to the clinical presentation, as he had no more kidney stones after initiation of the treatment.

\section{Discussion}

In most studies, it is assumed that increased calcitriol synthesis is at least partially responsible for hypercalciuria in acromegaly (8) (9) (10) (11). From rat studies, it is known that acromegaly promotes calcitriol synthesis, either through the effect of GH or through the effect of IGF1 or both (8) (10). Currently, it is assumed that IGF1 directly promotes renal $\alpha$-hydroxylase activity, leading to increased calcitriol levels and thus enhanced intestinal dietary calcium absorption with subsequent hypercalciuria (12) (13) (14). However, in a recent study, it has been shown that the calcitriol-mediated effect of acromegaly also involves increased distal tubular calcium

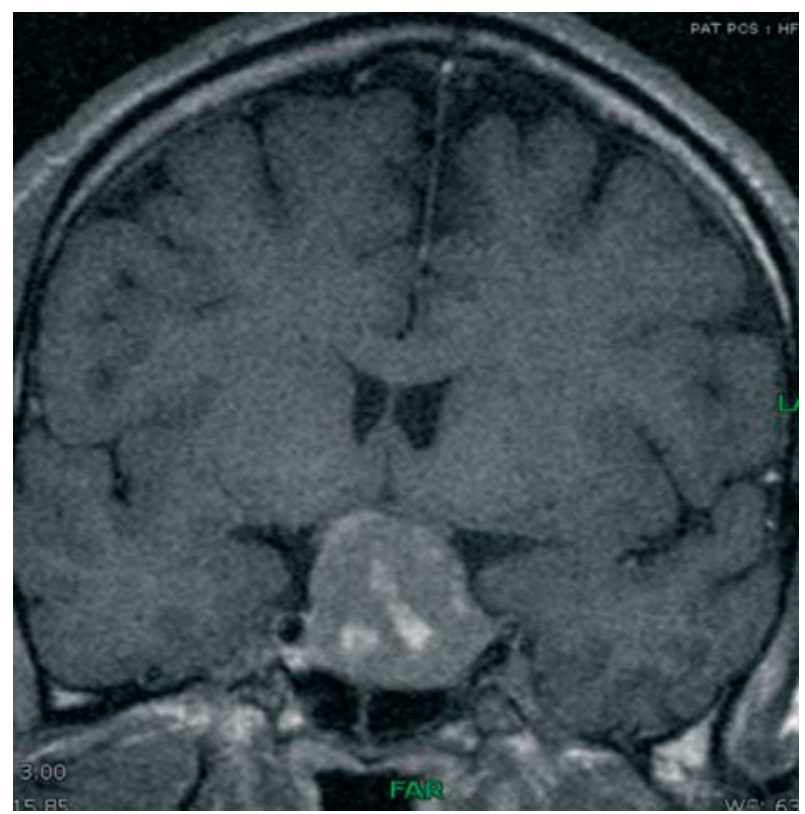

Figure 1

MRI scan showing a pituitary macro-adenoma with supra- and parasellar extension. 


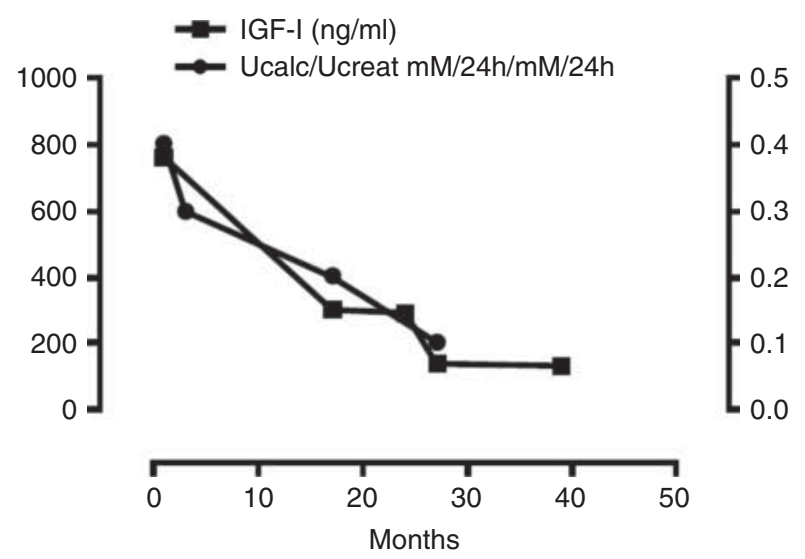

Figure 2

IGF1 and Ucalc/Ucreat in time.

reabsorption (3). So, in acromegaly, there is absorbtive hypercalciuria, which is only partly counteracted by increased distal tubular calcium reabsorbtion, leading to a net effect of hypercalciuria. The data presented in Fig. 2 are in full accordance with a primary role for IGF1 in the mechanism by which acromegaly leads to hypercalciuria.

PTH most likely has no causal role in the development of hypercalciuria in acromegaly. Most studies have reported low-normal PTH levels in uncontrolled acromegaly, which increase after adequate treatment (3) (15) (16). Others have reported normal PTH levels that are not specified (11) (17). One study found high PTH levels in acromegalic patients that increase slightly after treatment, which is also suggestive of no causal role for PTH (9).

It is evident that hypercalciuria occurs in acromegaly, and therefore, one would expect a high incidence of nephrolithiasis in acromegaly. There are, however, surprisingly few case reports of urolithiasis in acromegaly. Auriemma et al. (2) reviewed the mechanism of kidney stones with respect to acromegaly. They found hypercalciuria, hyperoxaluria and hypercitraturia and explained the low incidence of urolithiasis by the presence of hypercitraturia, which prevents the formation of urolithiasis (18) (19) (20). In the patient described here, urinary citrate concentration also decreased after controlling his acromegaly, which supports the mechanism observed by Auriemma et al. However, in our case, renal colic disappeared completely in parallel with a lowering of citraturia, suggesting that hypercalciuria was the driving force of renal stone formation in our patient.

Recently, it has been suggested that bone is an active regulator of energy and glucose metabolism (21). Iba et al. (22) first described a correlation between metabolic syndrome and hypercalciuria in animals. Liborio et al. (23) have recently investigated the correlation between insulin resistance and hypercalciuria in acromegaly. Insulin resistance appears to be associated with hypercalciuria, but it is still unclear whether this association is causal, as active acromegaly is associated with both insulin resistance and hypercalciuria. Perhaps both hypercalciuria and insulin resistance are merely symptoms of the same underlying active disease. The patient we describe here became normoglycemic without medication after control of his acromegaly, and therefore, we cannot draw a clear conclusion regarding the possible causal role of insulin resistance in the development of hypercalciuria in acromegaly. In our opinion, there are no strong arguments to suggest a role for insulin resistance as a cause for hypercalciuria in acromegaly.

In conclusion, we describe a patient in whom the presence of hypercalciuric kidney stones led to the diagnosis of acromegaly and in whom the kidney stones vanished after treatment of his acromegaly. This case is in full accordance with a primary role of IGF1-mediated, PTH-independent increase in calcitriol synthesis resulting in hypercalciuric kidney stones.

\section{Declaration of interest}

The authors declare that there is no conflict of interest that could be perceived as prejudicing the impartiality of the research reported.

\section{Funding}

This research did not receive any specific grant from any funding agency in the public, commercial or not-for-profit sector.

\section{Patient consent}

Written informed consent was obtained from the patient for publication of this case report.

\section{Author contributions}

E van der Valk was responsible for case description, literature review and writing. T Tobe was the patient's physician and was responsible for editing. A Stades was responsible for literature review and editing. A Muller was the physician of the patient and was responsible for literature review, writing and editing.

\section{References}

1 Chanson P, Salenave S, Kamenicky P, Cazabat L \& Young J 2009 Pituitary tumours: acromegaly. Best Practice \& Research. Clinical Endocrinology \& Metabolism 23 555-574. (doi:10.1016/j.beem. 2009.05.010) 
2 Auriemma RS, Galdiero M, De Martino MC, De Leo M, Grasso LF, Vitale P, Cozzolino A, Lombardi G, Colao A \& Pivonello R 2010 The kidney in acromegaly: renal structure and function in patients with acromegaly during active disease and 1 year after disease remission. European Journal of Endocrinology 162 1035-1042. (doi:10.1530/ EJE-10-0007)

3 Kamenicky P, Blanchard A, Gauci C, Salenave S, Letierce A, Lombes M, Brailly-Tabard S, Azizi M, Prie D, Souberbielle JC et al. 2012 Pathophysiology of renal calcium handling in acromegaly: what lies behind hypercalciuria? Journal of Clinical Endocrinology and Metabolism 97 2124-2133. (doi:10.1210/jc.2011-3188)

4 Pines A \& Olchovsky D 1985 Urolithiasis in acromegaly. Urology 26 240-242. (doi:10.1016/0090-4295(85)90118-9)

5 Heilberg IP, Czepielewski MA, Ajzen H, Ramos OL \& Schor N 1991 Metabolic factors for urolithiasis in acromegalic patients. Brazilian Journal of Medical and Biological Research 24 687-696.

6 Ieki Y, Miyakoshi H, Nagai Y, Bando Y, Usuda R, Miyamoto I, Ohsawa K \& Kobayashi K 1991 The frequency and mechanisms of urolithiasis in acromegaly. Nihon Naibunpi Gakkai Zasshi 67 755-763.

7 de Gennes, Bricaire H, Tourneur R, Moreau L \& Boutelier D 1961 Renal lithiasis in an acromegalic patient. Role of somatotropic hormone in the mechanism of hypercalciuria. Journal of Urology and Nephrology 67 75-77.

8 Spanos E, Barrett D, MacIntyre I, Pike JW, Safilian EF \& Haussler MR 1978 Effect of growth hormone on vitamin D metabolism. Nature 273 246-247. (doi:10.1038/273246a0)

9 White HD, Ahmad AM, Durham BH, Chandran S, Patwala A, Fraser WD \& Vora JP 2006 Effect of active acromegaly and its treatment on parathyroid circadian rhythmicity and parathyroid target-organ sensitivity. Journal of Clinical Endocrinology and Metabolism 91 913-919. (doi:10.1210/jc.2005-1602)

10 Sigurdsson G, Nunziata V, Reiner M, Nadarajah A \& Joplin GF 1973 Calcium absorption and excretion in the gut in acromegaly. Clinical Endocrinology 2 187-192. (doi:10.1111/j.1365-2265.1973. tb00418.x)

11 Takamoto S, Tsuchiya H, Onishi T, Morimoto S, Imanaka S, Mori S, Seino Y, Uozumi T \& Kumahara Y 1985 Changes in calcium homeostasis in acromegaly treated by pituitary adenomectomy. Journal of Clinical Endocrinology and Metabolism 61 7-11. (doi:10.1210/ jcem-61-1-7)

12 Nesbitt T \& Drezner MK 1993 Insulin-like growth factor-I regulation of renal 25-hydroxyvitamin D-1-hydroxylase activity. Endocrinology 132 133-138. (doi:10.1210/en.132.1.133)
13 Gomez JM 2006 The role of insulin-like growth factor I components in the regulation of vitamin D. Current Pharmaceutical Biotechnology 7 125-132. (doi:10.2174/138920106776597621)

14 Suzuki Y, Landowski CP \& Hediger MA 2008 Mechanisms and regulation of epithelial $\mathrm{Ca}^{2+}$ absorption in health and disease. Annual Review of Physiology 70 257-271. (doi:10.1146/annurev.physiol.69.031905.161003)

15 Shah R, Licata A, Oyesiku NM \& Ioachimescu AG 2012 Acromegaly as a cause of 1,25-dihydroxyvitamin D-dependent hypercalcemia: case reports and review of the literature. Pituitary 15 (Suppl 1) S17-S22. (doi:10.1007/s11102-010-0286-8)

16 Cappelli C, Gandossi E, Agosti B, Cerudelli B, Cumetti D, Castellano M, Pirola I, De Martino E \& Rosei EA 2004 Long-term treatment of acromegaly with lanreotide: evidence of increased serum parathormone concentration. Endocrine Journal 51 517-520. (doi:10.1507/endocrj.51.517)

17 Ezzat S, Melmed S, Endres D, Eyre DR \& Singer FR 1993 Biochemical assessment of bone formation and resorption in acromegaly. Journal of Clinical Endocrinology and Metabolism 76 1452-1457. (doi:10.1210/jc. 76.6.1452)

18 Park S \& Pearle MS 2007 Pathophysiology and management of calcium stones. Urologic Clinics of North America 34 323-334. (doi:10.1016/j.ucl. 2007.04.009)

19 Pak CY, Adams-Huet B, Poindexter JR, Pearle MS, Peterson RD \& Moe OW 2004 Rapid communication: relative effect of urinary calcium and oxalate on saturation of calcium oxalate. Kidney International 66 2032-2037. (doi:10.1111/j.1523-1755.2004.00975.x)

20 Caudarella R, Vescini F, Buffa A \& Stefoni S 2003 Citrate and mineral metabolism: kidney stones and bone disease. Frontiers in Bioscience $\mathbf{8}$ s1084-s1106. (doi:10.2741/1119)

21 Fernandez-Real JM \& Ricart W 2011 Osteocalcin: a new link between bone and energy metabolism. Some evolutionary clues. Current Opinion in Clinical Nutrition and Metabolic Care 14 360-366. (doi:10.1097/MCO Ob013e328346df4e)

22 Iba A, Kohjimoto Y, Mori T, Kuramoto T, Nishizawa S, Fujii R, Nanpo Y, Matsumura N, Shintani Y, Inagaki T et al. 2010 Insulin resistance increases the risk of urinary stone formation in a rat model of metabolic syndrome BJU International 106 1550-1554. (doi:10.1111/j.1464-410X. 2010.09216.x)

23 Liborio AB, Figueiredo PR, Montenegro Junior RM, Montenegro RM, Martins MR, Silva Junior GB, Porto IA, Mota JI \& Daher E 2012 Urinary calcium excretion and insulin resistance in patients with acromegaly. International Urology and Nephrology 44 1473-1477. (doi:10.1007/ s11255-011-0116-6)

Received in final form 16 April 2013

Accepted 29 April 2013 